in vivo $35: 417-422(2021)$

doi:10.21873/invivo.12273

\title{
Prognostic Factors After Surgical Treatment of Liver Metastases from Breast Cancer - 19 Years of Experience
}

\author{
KRISTÝNA PROCHÁZKOVÁ ${ }^{1}$, KRISTÝNA PIVOVARČÍKOVÁ ${ }^{2}$, MILENA ROUŠAROVÁ $^{3}$, \\ JOSEF VODIČKA ${ }^{1}$, PETR HOŠEK ${ }^{4}$, INKA TŘEŠKOVÁ ${ }^{5}$, ONDŘEJ HES ${ }^{2}$, \\ RADEK KUČERA ${ }^{6}$, ONDŘEJ TOPOLČAN ${ }^{5}$ and VLADISLAV TŘEŠKA ${ }^{1}$ \\ ${ }^{1}$ Department of Surgery, Faculty of Medicine in Pilsen, \\ Charles University and University Hospital, Pilsen, Czech Republic; \\ ${ }^{2}$ Department of Pathology, Faculty of Medicine in Pilsen, \\ Charles University and University Hospital, Pilsen, Czech Republic; \\ ${ }^{3}$ Czech National Oncological Register, Pilsen, Czech Republic; \\ ${ }^{4}$ Biomedical Center, Faculty of Medicine in Pilsen, Charles University, Pilsen, Czech Republic; \\ ${ }^{5}$ Department of Plastic Surgery, Faculty of Medicine in Pilsen, \\ Charles University and University Hospital, Pilsen, Czech Republic; \\ ${ }^{6}$ Department of Immunochemistry Diagnostics Faculty of Medicine in Pilsen, \\ Charles University and University Hospital, Pilsen, Czech Republic
}

\begin{abstract}
Background/Aim: The aim of this study was to determine the importance of surgical treatment, utility of hormone receptor status and selected biomarkers in the prognosis of patients with liver metastases from breast cancer (BCLM). Patients and Methods: Thirty female underwent surgery for BCLM between 1/2000 and 1/2019. Results: The type of surgery (resection/radiofrequency ablation) had no impact on overall survival (OS) ( $p=0.894)$. Having more than one BCLM ( $p=0.003)$, expression of human epidermal receptor 2 in metastases $(p=0.034)$, as well as an elevated presurgical level of carbohydrate antigen $19-9(p=0.017)$ and postsurgical thymidine kinase $(p=0.034)$ were negative prognostics factor for recurrence-free survival. The factors affecting OS included the number of liver procedures $(p=0.021)$, the degree of proliferative activity $(p=0.008)$ and elevated postsurgical carcinoembryonic antigen level $(p=0.038)$. Conclusion: The type of surgery had no impact on OS.
\end{abstract}

This article is freely accessible online.

Correspondence to: Radek Kucera (ORCID: 0000-0002-27392302), Ph.D., Associate Professor, Department of Immunochemistry Diagnostics, University Hospital Pilsen, Dr. E. Benese 1128/13, 305 99 Pilsen, Czech Republic. Tel: +420 603456958, e-mail: kucerar@fnplzen.cz

Key Words: Breast cancer, liver metastases, biomarkers, hormone receptor status, liver resection, prognostic markers.
Markers and hormonal status of liver metastases are important factors affecting prognosis.

Liver metastases occur in approximately $50 \%$ of patients who develop breast cancer metastases. Furthermore, liver metastases have one of the worst prognoses of all types of breast cancer metastases, with a 5-year survival rate of 0 to $12 \%$ (1). In the case of systemic treatment only, the median survival rate ranges between 3 and 16 months (2). However, there is growing evidence that survival increases after a combination of chemotherapy and surgical treatment, with 5-year survival rates exceeding $40 \%$ in some studies (3). These survival rates are comparable to those observed after resection of colorectal liver metastases (CLM) (4).

Even though the hormone receptor status (HRS) is one of the key factors taken into consideration when determining breast cancer treatment, results from different studies are heterogeneous and even conflicting. The majority of authors reported shorter survival in the absence of expression of progesterone (PR) and oestrogen receptors (ER), due to a poorer response to hormonal therapy (5). Little information is available, however, on whether survival is influenced by ER and PR conversion in breast cancer metastases.

The present study was conducted to determine the usability of HRS, human epidermal receptor 2 (HER2/neu) expression and other selected biomarkers in the prognosis of patients with breast cancer liver metastases (BCLM). We paid particular attention to the conversion of the receptor status between the primary tumour and metastases and to its 
impact on the recurrence-free (RFS) and overall (OS) survival of the patients.

\section{Patients and Methods}

In the time period of January 2000 - January 2019, surgical treatment of BCLM was performed on 30 women at the Department of Surgery, University Hospital in Pilsen. Their clinical characteristics are summarized in Table I. The postoperative (30 days) morbidity was $0.03 \%$ (one case of postoperative hematoma). There was no postoperative mortality. The median duration of follow-up was 66.0 months.

Immunohistochemistry methods used. All immunohistochemical staining was performed at a single laboratory (University Hospital Pilsen) using a Ventana Benchmark XT automated stainer (Ventana Medical System, Inc., Tucson, AZ, USA). The following primary antibodies were used: ER (monoclonal, clone Sp1, RTU; Ventana), PR (monoclonal, clone IE2; Ventana), Ki-67 (monoclonal, clone E3 ubiquitin-protein ligase MIB1; Ventana), HER2/neu (monoclonal, clone 4B5; Ventana), and E-cadherin (monoclonal, clone EP6; Biocare Medical, Concord, CA, USA). Primary antibodies were visualized using a supersensitive streptavidin-biotin-peroxidase complex (BioGenex, Fremont, CA, USA). Internal biotin was blocked using the standard protocol for the Ventana Benchmark XT automated stainer (hydrogen peroxide-based). Appropriate positive and negative controls were also used. The percentage of positively stained cells was estimated. For ER, PR and Ki-67, only nuclear positivity was considered as positive staining. Any nuclear positivity was considered as a positive result. For E-cadherin and HER2/neu, only membranous positivity was considered a positive result. The intensity of staining was compared with a positive external and internal control (if available).

Immunoassays and instruments used. Peripheral venous blood using the VACUETTE system (Greiner Bio-one Company, Kremsmünster, Austria) was collected before and after the treatment of BCLM. Serum tumour markers carcinoembryonic antigen (CEA) and carbohydrate antigen 19-9 (CA 19-9) were determined using the following immunochemical kits and instruments: Chemiluminescent assays ACCESS CEA and ACCESS CA 19-9 (Beckman Coulter, Brea, CA, USA) for DxI 800 (Beckman Coulter, Brea, CA, USA) and enzymoradiometric assay TK REA (Immunotech, Prague, Czech Republic) for Stratec SR 300 (Stratec SE, Birkenfeld, Germany).

RFS and OS definition and statistical methods used. RFS and OS after surgery of BCLM were selected as indicators of treatment outcome. RFS was defined from the time of BCLM surgery (the first surgical treatment in the case of multi-stage surgery) to the time of first recurrence, or death. OS was defined from the time of BCLM surgery to the time of death. The following key factors and their influence on RFS/OS were evaluated: Type of surgery [liver resection/radiofrequency ablation (RFA) plus liver resection]; HRS, ER and PR; HER2; E-cadherin; MIB1 status; CEA level; CA 19-9 level; thymidine kinase (TK) level.

The relationships between the evaluated factors and RFS/OS were analysed using a univariable Cox proportional hazards model. When the existence of a relationship was indicated, a cut-off level for the continuous variable was determined by an automated optimization process designed to find the cut-off level providing the
Table I. Basic characteristics of the patients $(n=30)$.

\begin{tabular}{llc}
\hline Characteristic & & Value \\
\hline Age at breast surgery, years & Median (range) & $47.6(30.0-72.3)$ \\
Histology of primary & DIC & $24(80.0 \%)$ \\
tumour, n (\%) & LIC & $1(3.3 \%)$ \\
& Other & $1(3.3 \%)$ \\
& Not available & $4(13.3 \%)$ \\
TNM stage at diagnosis*, & T1 & $10(33.3 \%)$ \\
n (\%) & T2 & $13(43.3 \%)$ \\
& T3 & 0 \\
& T4 & $3(10.0 \%)$ \\
& Not available & $4(13.3 \%)$ \\
& N0 & $9(30.0 \%)$ \\
& N1 & $17(56.7 \%)$ \\
& Nx & $4(13.3 \%)$ \\
& M0 & $29(96.7 \%)$ \\
TTP, months & M1 & $1(3.3 \%)$ \\
Size of metastasis, mm & Median (95\% CI) & $57.3(35.9-72.8)$ \\
Age liver surgery, years & Median (range) & $30(7.0-75.0)$ \\
RFS, months & Median (range) & $54.5(33.1-73.2)$ \\
OS, months & Median (95\% CI) & $10.3(5.8-20.7)$ \\
& Median (95\% CI) & $56.3(31.4-78.6)$
\end{tabular}

CI: Confidence intervaI; DIC: ductal invasive carcinoma; LIC: lobular invasive carcinoma; RFA: radiofrequency ablation; TTP: time to progression after breast surgery, RFS: recurrence-free survival (time to progression after liver surgery); OS: overall survival. *According to the eighth edition of the TNM Classification of Malignant Tumours (22).

lowest Cox-Mantel $p$-value after a Kaplan-Meier analysis. Categorical factors were analysed using the Kaplan-Meier method. Survival rates and medians at 3 and 5 years were calculated by linear interpolation of the appropriate Kaplan-Meier survival curve estimation; the median follow-up was determined by the inverse Kaplan-Meier method for OS data. The entire statistical analysis was performed using STATISTICA (version $11 \mathrm{Cz}$; TIBCO Software Inc., Palo Alto, CA, USA) and Matlab (version 2014b; The MathWorks, Inc., Natick, MA, USA). All reported $p$-values are twotailed and the level of statistical significance was set at $\alpha=0.05$.

\section{Results}

Receptor status, including the impact of receptor status conversion, is summarized in Table II. We observed a conversion in PR status between primary tumour and metastases (using a $1 \%$ threshold) in a total of 10 cases, with six conversions from positive to negative and four from negative to positive. Similar conversion was also observed in ER status, from positive to negative in seven, and from negative to positive in three. Subsequently, we observed the conversion of HER2/neu from positive to negative in one case and from negative to positive in two. E-Cadherin status was converted to negative in all seven positive cases. Analysis indicated a borderline negative influence of ER conversion on RFS $(\mathrm{p}=0.057)$. 
Table II. Comparison of the receptor expression between the primary tumour and metastases and the impact of conversions on recurrence-free (RFS) and overall survival (OS).

\begin{tabular}{|c|c|c|c|c|c|}
\hline & \multicolumn{2}{|c|}{ Primary tumour, n (\%) } & \multirow[t]{2}{*}{ Metastasis, $\mathrm{n}(\%)$} & \multicolumn{2}{|c|}{$p$-Value } \\
\hline & & & & RFS & OS \\
\hline \multirow[t]{3}{*}{ ER } & Positive & $22(73.3 \%)$ & $15(50.0 \%)$ & 0.057 & 0.278 \\
\hline & Negative & $7(23.3 \%)$ & $11(36.7 \%)$ & & \\
\hline & NA & $1(3.33 \%)$ & $4(13.3 \%)$ & & \\
\hline \multirow[t]{3}{*}{ PR } & Positive & $18(60.0 \%)$ & $13(43.3 \%)$ & 0.678 & 0.650 \\
\hline & Negative & $11(36.7 \%)$ & $13(43.3 \%)$ & & \\
\hline & NA & $1(3.33 \%)$ & $4(13.3 \%)$ & & \\
\hline \multirow[t]{3}{*}{ HER2/neu } & Positive & $9(30.0 \%)$ & $9(30.0 \%)$ & 0.501 & 0.912 \\
\hline & Negative & $17(56.7 \%)$ & $15(50.0 \%)$ & & \\
\hline & NA & $4(13.3 \%)$ & $6(20.0 \%)$ & & \\
\hline \multirow[t]{3}{*}{ E-Cadherin } & Positive & $27(90.0 \%)$ & $17(56.7 \%)$ & 0.207 & 0.886 \\
\hline & Negative & $3(10.0 \%)$ & $10(33.3 \%)$ & & \\
\hline & NA & $0(0 \%)$ & $3(10.0 \%)$ & & \\
\hline
\end{tabular}

NA: Not available; ER: estrogen receptor; PR: progesterone receptor; HER2/neu - human epidermal growth factor receptor 2; E-cadherin: epithelial cadherin. RFS and OS $p$-values: Gehan-Wilcoxon test between patients with conversion (of either direction) and without conversion.

Three- and 5-year RFS were $15.1 \%$ and $6.2 \%$, respectively, whilst the corresponding OS rates were $67.6 \%$ and $39.3 \%$, respectively.

The results of the analysis of survival according to selected prognostic factors are presented in Figure 1. A statistically significant prognostic factor affecting RFS was the type of surgery (RFA or RFA with resection versus complete resection alone $(p=0.016)$ but it had no impact on OS ( $p=0.894$ ) (Figure 1A). We found the following negative prognostic markers for RFS: higher serum level of CA 19-9 before liver surgery (Cox model: $p=0.017$; Figure 1D), and higher serum level of TK after liver surgery (Cox model: $p=0.034$; Figure 1C). For OS, negative prognostic markers were high MIB1 activity in breast tumour tissue (Cox model: $p=0.008$; Figure 1D), and high serum CEA level (Cox model: $p=0.038$; Figure 1E) after liver surgery.

\section{Discussion}

Breast cancer can no longer be considered a homogenous disease. More than any other type of cancer, BCLM requires a multidisciplinary approach and personalised treatment (3).

The results of previous studies are rather conflicting regarding receptor status and prognosis. In a study by Lubrano et al., negative HRS in both the primary tumour and BCLM appeared to be strongly associated with an increased survival rate (6). In contrast, Elias et al. reported that a positive HRS was the most significant positive prognostic factor in their study (7). According to Martinez et al., the presence of ER and HER2 in BCLM was associated with increased survival. Conversely, the PR status of the metastatic site did not significantly impact survival (8).
Moreover, the occurrence of phenotypic discordance in HRS between primary and recurrent breast cancer has been reported (9). Previous studies used a 10\% threshold for the positivity of ER and PR. When using the new 1\% ER and PR threshold according to the American Society of Clinical Oncology guidelines (10), the conversion rate is even higher. While ER and PR conversion can be the result of discordant laboratory testing (11), or the development of resistance to specific treatment, this cannot be claimed for HER2/neu expression. Nevertheless, in a few cases from our sample, conversion from negative to positive occurred. This phenomenon has also been documented (12) but is more difficult to explain. Perhaps small receptor-positive clones within the primary tumour preferentially metastasized in these cases (13). Alternatively, this phenomenon might be a result of genetic drift during tumour progression (14).

How does conversion affect prognosis? According to the study by Hoefnagel et al., the OS of patients showing conversion from positive to negative ER or PR, or from negative to positive ER or PR, or remaining negative was comparable, but was significantly worse than that of the patients whose ER and PR expression remained positive (15). We did not observe a statistically significant effect of conversion on prognosis.

OS after BCLM surgery is considered to be the main treatment outcome indicator. Adam et al. recommend neoadjuvant chemotherapy for patients with planned liver resection (16). Analysing this factor, we observed no impact of neoadjuvant therapy on the survival outcome in our cohort.

The review by Yoo et al., which is currently the largest to date, demonstrated acceptable 3-year OS (56\%) and 5-year OS $(37 \%)$ among 1,686 patients who underwent liver resection of 

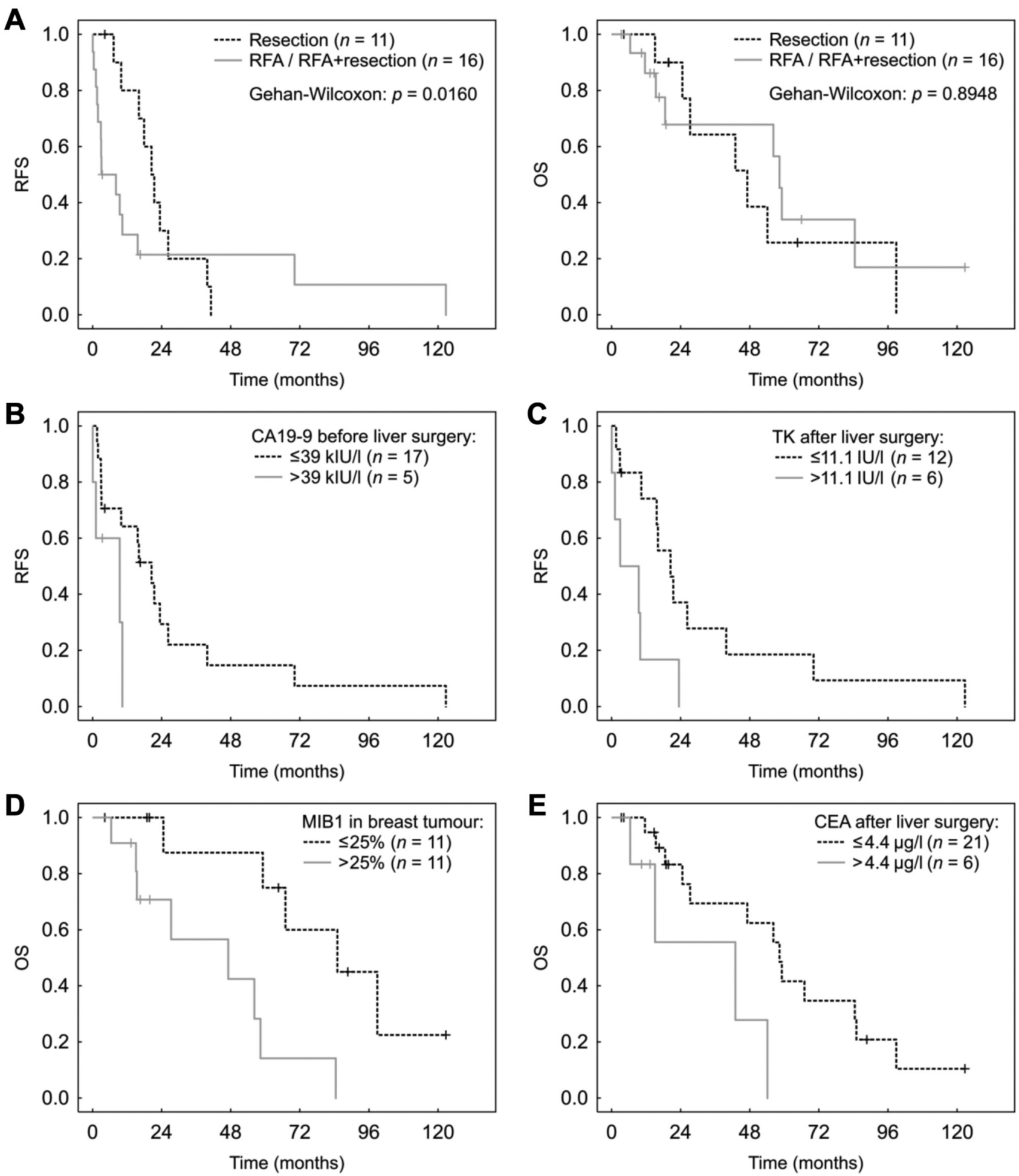

Figure 1. Prognostic value of surgical approach (A), carbohydrate antigen 19-9 (CA 19-9) level before liver surgery (B), thymidine kinase (TK) level after surgery $(C)$, E3 ubiquitin-protein ligase MIB1 (MIB1) in breast tumour (D), and carcinoembryonic antigen (CEA) after liver surgery (E). Negative prognostic markers of recurrence-free (RFS) were an elevated presurgical CA 19-9 level and elevated TK level after liver surgery. Negative prognostic markers of overall survival (OS) were high MIB1 activity and elevated CEA level after liver surgery. p-Values are not shown in $B-E$ as the threshold values used for the stratification producing the survival plots were optimized to provide the lowest p-value. Statistical significance of the factors shown here was assessed by univariable Cox proportional hazards model and is presented in the Results section. 
BCLM (17). Our even slightly better results, of 3-year OS of $67.6 \%$ and 5 -year OS of $39.3 \%$, can be attributed to the strictly individual use of both surgical techniques (resection and RFA) as well as to the use of repeated surgery for recurrent liver metastases, which has become standard practice and which improves survival $(16,18)$.

We identified negative prognostic markers for RFS that are in accordance with the existing literature: An elevated presurgical CA 19-9 level and an elevated TK level after liver surgery. Negative prognostic markers for OS were a high MIB1 activity and an elevated CEA level after liver surgery (19-21).

In conclusion, the outcome we observed for surgical treatment of BCLM is similar to the results reported for CLM. Surgical treatment for BCLM is an important part of multimodal therapy and should be considered for all patients when technically feasible. According to our results, repeated surgery of BCLM provides a higher survival rate. It seems that metastatic disease may change characteristics, and the HRS should therefore always be investigated at the time of diagnosis of metastatic disease before deciding on the course of treatment. In most cases, our patients not only had tumours with poor prognosis, but were often also mothers, which certainly adds to the gravity of the situation.

The main limitations of our study are its retrospective design and the limited sample size from a single centre. Larger cohorts are necessary to precisely confirm our results.

\section{Conflicts of Interest}

The Authors have no conflicts of interest to declare.

\section{Authors' Contributions}

Conceptualization: KP and KP; methodology KP, PH and $\mathrm{RK}$; investigation: $\mathrm{KP}, \mathrm{KP}, \mathrm{MR}$ and $\mathrm{OH}$; writing - original draft preparation: $\mathrm{KP}, \mathrm{KP}$, and $\mathrm{PH}$; writing - review and editing: RK, OT, IT, JV and VT.

\section{Acknowledgements}

This study was supported by grant SVV-2020-2022 no. 260539, the Charles University Research Fund (Progres Q39), a grant of the Ministry of Health of the Czech Republic - Conceptual Development of Research Organization (Faculty Hospital in Pilsen - FNPI 00669806) and by Centrum of Clinical and Experimental Liver Surgery UNCE/MED/006 provided by Charles University.

\section{References}

1 Ruiz A, Wicherts DA, Sebagh M, Giacchetti S, Castro-Benitez $\mathrm{C}$, van Hillegersberg R, Paule B, Castaing D, Morère J-F and Adam R: Predictive profile-nomogram for liver resection for breast cancer metastases: An aggressive approach with promising results. Ann Surg Oncol 24(2): 535-545, 2017. PMID: 27573523. DOI: $10.1245 / \mathrm{s} 10434-016-5522-7$

2 Follana $\mathrm{P}$, Barrière J, Chamorey E, Largillier R, Dadone B, Mari V, Hannoun-Levi JM, Marcy M, Flipo B and Ferrero J-M: Prognostic factors in 401 elderly women with metastatic breast cancer. Oncology 86(3): 143-151, 2014. PMID: 24577186. DOI: $10.1159 / 000357781$

3 Golse $\mathrm{N}$ and Adam R: Liver metastases from breast cancer: What role for surgery? indications and results. Clinical Breast Cancer 17(4): 256-265, 2017. PMID: 28196771. DOI: 10.1016/ j.clbc.2016.12.012

4 Treska V, Cerna M, Liska V, Treskova I, Narsanska A and Bruha J: Surgery for breast cancer liver metastases - factors determining results. Anticancer Res 34(3): 1281-1286, 2014. PMID: 24596373.

5 Treska V, Cerna M, Kydlicek T and Treskova I: Prognostic factors of breast cancer liver metastasis surgery. Arch Med Sci 11(3): 683-685, 2015. PMID: 26170865. DOI: 10.5114/aoms. 2015.52376

6 Lubrano J, Roman H, Tarrab S, Resch B, Marpeau L and Scotté M: Liver resection for breast cancer metastasis: Does it improve survival? Surgery Today 38(4): 293, 2008. PMID: 18368316. DOI: $10.1007 / \mathrm{s} 00595-007-3617-2$

7 Elias D, Maisonnette F, Druet-Cabanac M, Ouellet J-F, Guinebretiere J-M, Spielmann M and Delaloge S: An attempt to clarify indications for hepatectomy for liver metastases from breast cancer. Am J Surg 185(2): 158-164, 2003. PMID: 12559448. DOI: 10.1016/S0002-9610(02)01204-7

8 Martinez SR, Young SE, Giuliano AE and Bilchik AJ: The utility of estrogen receptor, progesterone receptor, and HER-2/neu status to predict survival in patients undergoing hepatic resection for breast cancer metastases. The Am J Surg 191(2): 281-283, 2006. PMID: 16442961. DOI:10.1016/j.amjsurg.2005.08.030

9 Caralt M, Bilbao I, Cortés J, Escartín A, Lázaro JL, Dopazo C, Olsina JJ, Balsells $\mathrm{J}$ and Charco R: Hepatic resection for liver metastases as part of the "oncosurgical" treatment of metastatic breast cancer. Ann Surg Oncol 15(10): 2804, 2008. PMID: 18670821. DOI: 10.1245/s10434-008-0072-2

10 Hammond MEH, Hayes DF, Dowsett M, Allred DC, Hagerty KL, Badve S, Fitzgibbons PL, Francis G, Goldstein NS, Hayes M, Hicks DG, Lester S, Love R, Mangu PB, McShane L, Miller K, Osborne CK, Paik S, Perlmutter J, Rhodes A, Sasano H, Schwartz JN, Sweep FCG, Taube S, Torlakovic EE, Valenstein P, Viale G, Visscher D, Wheeler T, Williams RB, Wittliff JL and Wolff AC: American Society of Clinical Oncology/College Of American Pathologists guideline recommendations for immunohistochemical testing of estrogen and progesterone receptors in breast cancer. J Clin Oncol 28(16): 2784-2795, 2010. PMID: 20404251. DOI: 10.1200/JCO.2009.25.6529

11 Hoefnagel LDC, van de Vijver MJ, van Slooten H-J, Wesseling P, Wesseling J, Westenend PJ, Bart J, Seldenrijk CA, Nagtegaal ID, Oudejans J, van der Valk P, van der Groep P, de Vries EGE, van der Wall E and van Diest PJ: Receptor conversion in distant breast cancer metastases. Breast Cancer Res 12(5): R75, 2010. PMID: 20863372. DOI: 10.1186/bcr2645

12 Liedtke C, Broglio K, Moulder S, Hsu L, Kau S-W, Symmans WF, Albarracin C, Meric-Bernstam F, Woodward W, Theriault RL, Kiesel L, Hortobagyi GN, Pusztai L and Gonzalez-Angulo AM: Prognostic impact of discordance between triple-receptor measurements in primary and recurrent breast cancer. Ann Oncol 
20(12): 1953-1958, 2009. PMID: 19596702. DOI: 10.1093/ annonc/mdp263

13 Kerbel RS: Growth dominance of the metastatic cancer cell: Cellular and molecular aspects. Adv Cancer Res 55: 87-132, 1990. PMID: 2167000. DOI: 10.1016/s0065-230x(08)60469-8.

14 Kuukasjärvi T, Karhu R, Tanner M, Kähkönen M, Schäffer A, Nupponen N, Pennanen S, Kallioniemi A, Kallioniemi O-P and Isola $\mathrm{J}$ : Genetic heterogeneity and clonal evolution underlying development of asynchronous metastasis in human breast cancer. Cancer Res 57(8): 1597-604, 1997. PMID: 9108466.

15 Hoefnagel LD, Moelans CB, Meijer SL, van Slooten HJ, Wesseling P, Wesseling J, Westenend PJ, Bart J, Seldenrijk CA, Nagtegaal ID, Oudejans J, van der Valk P, van Gils $\mathrm{CH}$, van der Wall E and van Diest PJ: Prognostic value of estrogen receptor $\alpha$ and progesterone receptor conversion in distant breast cancer metastases. Cancer 118(20): 4929-4935, 2012. PMID: 22415862. DOI: $10.1002 / \mathrm{cncr} .27518$

16 Adam R, Aloia T, Krissat J, Bralet M-P, Paule B, Giacchetti S, Delvart V, Azoulay D, Bismuth $\mathrm{H}$ and Castaing D: Is liver resection justified for patients with hepatic metastases from breast cancer? Ann Surg 244(6): 897-908, 2006. PMID: 17122615. DOI: 10.1097/01.sla.0000246847.02058.1b

17 Yoo TG, Cranshaw I, Broom R, Pandanaboyana S and Bartlett A: Systematic review of early and long-term outcome of liver resection for metastatic breast cancer: Is there a survival benefit? Breast 32: 162-172, 2017. PMID: 28193572. DOI: 10.1016/ j.breast.2017.02.003
18 Ruiz A, Castro-Benitez C, Sebagh M, Giacchetti S, Castro-Santa E, Wicherts DA, van Hillegersberg R, Paule B, Castaing D, Morère J-F and Adam R: Repeat hepatectomy for breast cancer liver metastases. Ann Surg Oncol 22 Suppl 3: S1057-66, 2015. PMID: 26259753. DOI: 10.1245/s10434-015-4785-8

19 Yazdani A, Dorri S, Atashi A, Shirafkan H and Zabolinezhad H: Bone metastasis prognostic factors in breast cancer. Breast Cancer 13: 1178223419830978, 2019. PMID: 30828246. DOI: $10.1177 / 1178223419830978$

20 Liska V, Holubec L Jr, Treska V, Vrzalova J, Skalicky T, Sutnar A, Kormunda S, Bruha J, Vycital O, Finek J, Pesta M, Pecen L and Topolcan O: Evaluation of tumour markers as differential diagnostic tool in patients with suspicion of liver metastases from breast cancer. Anticancer Res 31(4): 1447-1451, 2011. PMID: 21508401

21 Peng L, Zhang Z, Zhao D, Zhao J, Mao F and Sun Q: Discordance of immunohistochemical markers between primary and recurrent or metastatic breast cancer: A retrospective analysis of 107 cases. Medicine 99(25): e20738, 2020. PMID: 32569215. DOI: 10.1097/MD.0000000000020738

22 Brierley $J$, Gospodarowicz $M$ and Wittekind C: TNM Classification of Malignant Tumours (Eighth Edition). Wiley Blackwell, pp. 154-159, 2017.

Received September 10, 2020

Revised September 24, 2020

Accepted September 25, 2020 